www.nature.com/pj

\title{
A high-resolution solid-state NMR study on starch-clay nanocomposites and the effect of aging on clay dispersion
}

\author{
Xiaoqing Zhang, Katherine Dean and Iko M Burgar
}

High-resolution solid-state nuclear magnetic resonance (NMR) was applied as a bulk analysis method to provide an indication of clay dispersion in starch-clay nanocomposites. The starch composite containing $2.5 \mathrm{wt} \%$ nano-clay appeared as an exfoliated system with an average distance between clay platelets $(<\bar{D}>)$ of around $40 \mathrm{~nm}$. Increasing the amount of nano-clay to $5.0 \mathrm{wt} \%$ reduced the $\langle\bar{D}\rangle$ value to around $20 \mathrm{~nm}$. Aging displayed a minimal effect on the exfoliation of starch-clay nanocomposites. However, the $\langle\overline{\boldsymbol{D}}\rangle$ value became much larger on introduction of $5 \mathrm{wt} \%$ polyvinyl alcohol (PVOH) into the systems because of the formation of aggregated structures, and the $\langle\overline{\boldsymbol{D}}\rangle$ value increased further after aging. The motion of PVOH molecules during the aging period could function as a driving force toward a more stable interaction between PVOH chains and clay platelets, thus resulting in a reduction in the degree of clay exfoliation in the starch matrix.

Polymer Journal (2010) 42, 689-695; doi:10.1038/pj.2010.48; published online 2 June 2010

Keywords: aging effect; exfoliation; solid-state NMR; starch-clay nanocomposite

\section{INTRODUCTION}

Agriculture-based natural polymer products have become an important alternative raw material for replacing petroleum-based plastics because of their renewable and biodegradable nature. Starch, as one of the cheapest natural polymers, has been comprehensively investigated. ${ }^{1-3}$ Thermoplastic starch has been produced using conventional thermal extrusion methods at suitable temperatures using added plasticizers (usually water and glycerol), and, in many cases, other polymer additives to modify the properties of starch-based materials. ${ }^{4-13}$

Polymer-clay nanocomposites have attracted a great deal of interest by researchers in academia and industry, because significant improvements in many aspects of material performance can be obtained when using a very low dosing amount of such layered nanoparticles. ${ }^{14-19}$ The property improvements of these doped materials compared with pure polymers or conventional micro- or macrocomposites are due to the significantly strengthened interfacial interactions between polymer chains and nanoparticles (layer thickness of the order of $1 \mathrm{~nm}$, diameter of 30-1000 nm) when these particles are well dispersed in the polymer matrix. Layered silicates such as montmorillonite, hectorite and saponite are frequently used, and intercalated, flocculated or exfoliated nanocomposites are obtained on the basis of particle dispersion. Starch-clay nanocomposites have also been produced to enhance the mechanical and barrier properties through either solution casting or melt extrusion to achieve a sufficient dispersion of clay in the nanocomposites. ${ }^{19-29}$
High-resolution solid-state NMR is a powerful tool for obtaining valuable information on molecular motions, intermolecular interactions among different components in a multicomponent system and phase structures of multiphase materials. ${ }^{30-32}$ The interaction between polymer chains and clay platelets, as well as the dispersion of clay in polymer nano-clay composites, can also be explored through the examination of NMR spectra and ${ }^{1} \mathrm{H} \mathrm{T}_{1}$ proton spin-lattice relaxations, as established in recent years by VanderHart et al.; ${ }^{33-37}$ this method has been applied to nylon nano-clay composites. The same methodology was applied to starch-clay nanocomposites in this study to examine the clay dispersion in the starch matrix. This method also makes it relatively easy to study the effect of aging on clay dispersion, which has a strong influence on the material properties in applications, but has not been addressed in detail, to the best of our knowledge.

Starch-clay nanocomposites were produced by thermal extrusion with varied dosing amounts of sodium montmorillonite clay (NaMMT, nano-clay). As polyvinyl alcohol $(\mathrm{PVOH})$ has been demonstrated to be an effective modifier that is used in thermoplastic starch extrusion for improving processing capability and mechanical properties while maintaining biodegradability, ${ }^{29,38-40}$ starch-clay nanocomposites containing 5\% $\mathrm{PVOH}$ were also prepared under the same conditions. The clay dispersion behavior of these samples, which varied from exfoliated to intercalated systems, was examined by detecting the effect of paramagnetic impurity $\mathrm{Fe}^{3+}$ ions in the clay on solid-state NMR parameters, such as spectrum linewidth and 
relaxation times, of the starch matrix. The behavior was also compared with dispersion results as determined from transmission electron microscopy (TEM). For the aging effect study, samples were taken during the conditioning period under controlled conditions. The interactions between clay platelets and the starch matrix or the PVOH segments and the effects of moisture, starch molecular motions and starch recrystallization on clay dispersion during the aging process were also discussed, in conjunction with the issues of applying the solid-state NMR method to study polymer nano-clay composites.

\section{EXPERIMENTAL PROCEDURE}

\section{Materials}

Hydro-propylene-modified high-amylose corn starch from Penford Australia Limited (Lane Cove, NSW, Australia) and naturally occurring layered clay, NaMMT, obtained from Southern Clay Products (Tokyo, Japan) (Cloisite $\mathrm{Na}^{+}$) were used to produce starch-clay nanocomposites. PVOH (86.5-89.0\% hydrolyzed) with a molecular weight of $22000 \mathrm{~g} \mathrm{~mol}^{-1}$ was supplied by Gohsenol (Nippon Gohsei, Osaka, Japan). The extrusion producing thermoplastic starch and starch-NaMMT nanocomposites, the formulations of which are listed in Table 1 , was conducted at $110^{\circ} \mathrm{C}$ using a twin-screw extruder with a diameter of $30 \mathrm{~mm}$ and $L / D=40$, as described previously. ${ }^{29}$ Deionized water of $15 \mathrm{wt} \%$ was used as a plasticizer in all cases, and the nanocomposite samples were extruded into sheet form through a $0.5 \mathrm{~mm}$ die attached to the extruder. These samples were conditioned under standard relative humidity $(\mathrm{RH}=50 \%)$ at room temperature $\left(22^{\circ} \mathrm{C}\right)$, and on removal from the humidity tank were sealed in plastic bags and tested immediately (within 1-2 days). The moisture content of the samples was measured by comparing the sample weights before and after heating at $105^{\circ} \mathrm{C}$ for $3-5 \mathrm{~h}$.

\section{Instruments}

TEM images of nanocomposites were taken on a Philips CM30 TEM (Philips Research, Eindhoven, Netherlands) using an accelerating voltage of $100 \mathrm{keV}$ at magnifications of up to $\times 100000$ to examine the dispersion of the NaMMT clay particles. Samples were oven dried at $70^{\circ} \mathrm{C}$ for $24 \mathrm{~h}$ and then directly sectioned using a 45-degree diamond knife at room temperature. The $70 \mathrm{~nm}$ ribbons were carefully sandwiched between two copper grids for TEM imaging.

High-resolution solid-state NMR experiments were conducted at room temperature using a Varian Unity Plus spectrometer (Varian Australia Pty. Ltd., Mulgrave, VIC, Australia) at resonance frequencies of $75 \mathrm{MHz}$ for ${ }^{13} \mathrm{C}$ and of $300 \mathrm{MHz}$ for ${ }^{1} \mathrm{H} .{ }^{13} \mathrm{C}$ NMR spectra were observed under cross-polarization, magic angle spinning (CP/MAS) and high-power dipolar decoupling conditions. The $90^{\circ}$ pulse was $6 \mu$ for ${ }^{1} \mathrm{H}$ and ${ }^{13} \mathrm{C}$, whereas the spinning rate of MAS was set at a value in the range of $\sim 6 \mathrm{kHz}$. A contact time of $1.0 \mathrm{~ms}$ was used for measuring CP/MAS spectra. The chemical shift of ${ }^{13} \mathrm{C} C \mathrm{CP} / \mathrm{MAS}$ spectra was determined by taking the carbonyl carbon of solid glycine (176.3 p.p.m.) as an external reference standard. ${ }^{1} \mathrm{H}$ spin-lattice $\left(\mathrm{T}_{1}\right)$ data of the starch matrix were measured indirectly through the change in ${ }^{13} \mathrm{C}$ magnetization prepared by $\mathrm{CP}$ after the inversion-recovery pulse sequence in the ${ }^{1} \mathrm{H}$ channel, whereas the ${ }^{1} \mathrm{H}$ spin-lattice relaxation times in rotating frame $\left(\mathrm{T}_{1 \rho}\right)$ were measured by variation in spin-locking times in the ${ }^{1} \mathrm{H}$ channel before a fixed $\mathrm{CP}$ contact time of $1 \mathrm{~ms}$. The ${ }^{1} \mathrm{H} \mathrm{T}_{1}$ data of the moisture in the systems were measured directly by

Table 1 Compositions of the starch-clay nanocomposites

\begin{tabular}{lccc}
\hline Sample & Water (wt\%) & PVOH (wt\%) & NaMMT (wt\%) \\
\hline ST-0 & 15 & 0 & 0 \\
ST-N2.5 & 15 & 0 & 2.5 \\
ST-N5.0 & 15 & 0 & 5.0 \\
SP-0 & 15 & 5 & 0 \\
SP-N2.5 & 15 & 5 & 2.5 \\
SP-N5.0 & 15 & 5 & 5.0 \\
\hline
\end{tabular}

Abbreviations: NaMMT, sodium montmorillonite clay; PVOH, polyvinyl alcohol. detecting the variation of the ${ }^{1} \mathrm{H}$ intensity at $4.6-4.8$ p.p.m. by the inversionrecovery pulse sequence under the MAS condition.

${ }^{1} \mathrm{H} \mathrm{T} \mathrm{T}_{1}$ data of these nanocomposite samples were also measured in a static magnetic field using a Bruker Minispec PC 120 spectrometer (Bruker BioSpin Pty. Ltd., Alexandria, NSW, Australia) at $20 \mathrm{MHz}$ by the inversion-recovery pulse sequence. A $10 \mathrm{~mm}$ sample tube was used, whereas the $90^{\circ}$ pulse was $1.5 \mu \mathrm{s}$, with a repetition time of $1 \mathrm{~s}$. Data analysis was conducted using IGOR program from WaveMetrics Inc. (Portland, OR, USA).

\section{RESULTS AND DISCUSSION}

Clay dispersion in starch-clay nanocomposites and its effect on solid-state NMR parameters

Because of strong ion-dipolar interactions between the $\mathrm{Na}^{+}$of NaMMT and the hydroxyl groups of plasticized/gelatinized starch, sufficient clay dispersion in the starch matrix was achieved under thermal extrusion conditions as studied by X-ray diffraction and TEM. ${ }^{29}$ However, the situation became different when a small amount of $\mathrm{PVOH}$ was introduced into the system. Figure 1 shows TEM images of starch-clay nanocomposites with or without PVOH after aging for 105 days. Many single clay platelets and small tactoids were observed for starch with $2.5 \mathrm{wt} \%$ of NaMMT (ST-N2.5), whereas the addition of $5 \mathrm{wt} \%$ of $\mathrm{PVOH}$ to the system generated numerous larger tactoids (SP-N2.5). This was attributed to the interaction between NaMMT and $\mathrm{PVOH}$ chains becoming predominant when $\mathrm{PVOH}$ was added into the system, resulting in intercalated structures with $\mathrm{PVOH}$ segments driven between different clay layers and the formation of clay agglomerates. ${ }^{29}$ When the amount of NaMMT was increased to $5.0 \mathrm{wt} \%$, ST-N5.0 still seemed to be an exfoliated system, but further larger clay aggregates were observed in the SP-N5.0 sample, showing the effect of $\mathrm{PVOH}$ on clay dispersion in the starch matrix.
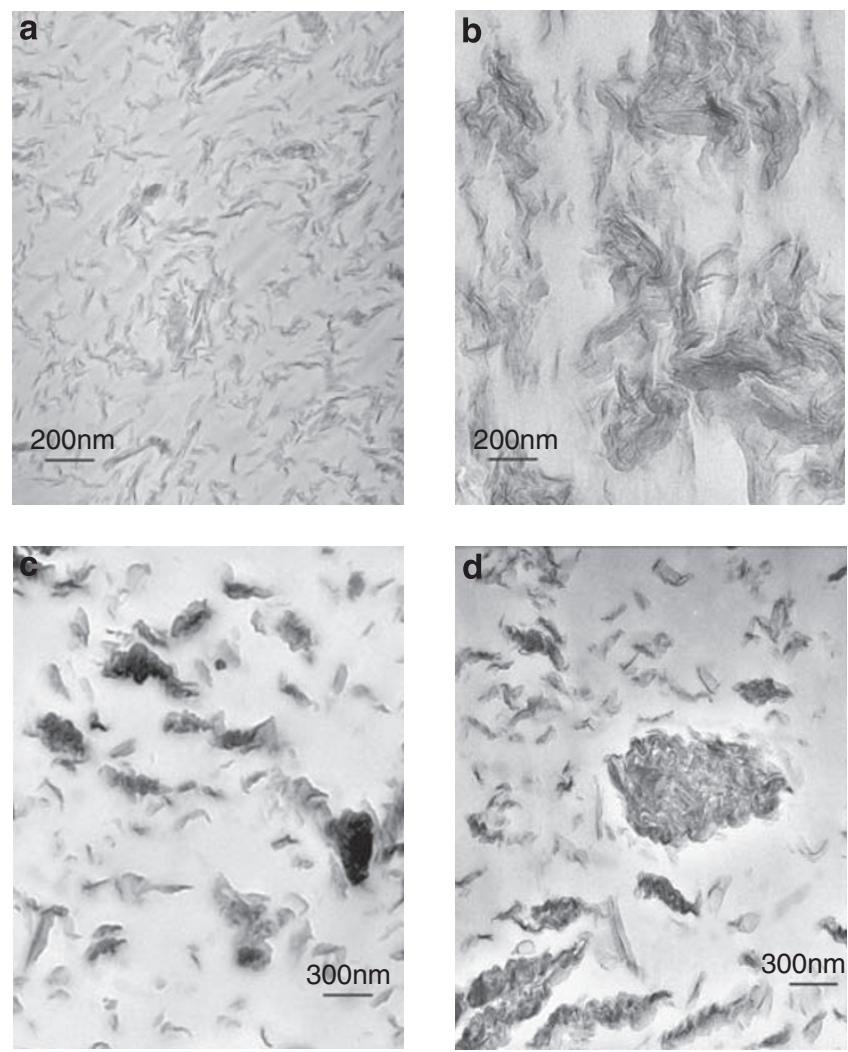

Figure 1 TEM images of starch-clay nanocomposites after aging for 105 days. (a) ST-N2.5, (b) ST-N5.0, (c) SP-N2.5 and (d) SP-N5.0. 
As described by VanderHart et al., ${ }^{33-36}$ naturally occurring montmorillonite clays usually contain $2-5 \mathrm{wt} \%$ of paramagnetic $\mathrm{Fe}^{3+}$ ions, which are mainly substituted into octahedral $\mathrm{Al}^{3+}$ sites. These $\mathrm{Fe}^{3+}$ ions have no influence on the embedded charge, but they exert a sizable influence on the nuclear spin near the clay surface. As the clay layer is only about $1 \mathrm{~nm}$, the polymer chains directly interacting with the clay surface will be influenced by $\mathrm{Fe}^{3+}$ ions. When the amount of $\mathrm{Fe}^{3+}$ is sufficient (the $\mathrm{Fe}_{2} \mathrm{O}_{3}$ content in NaMMT was $4.28 \mathrm{wt} \%$, as detected by ICP) and the distance between $\mathrm{Fe}^{3+}$ and the studied nuclei is close enough, significant signal weakening and linewidth broadening will occur for these nuclei, in conjunction with remarkable shortening of their ${ }^{1} \mathrm{H} \mathrm{T}_{1}$ or even ${ }^{1} \mathrm{H} \mathrm{T}_{1 \rho}$ values. Through strong proton spin-diffusion interactions among the polymer matrix, such effects can penetrate into the protons farther away from the clay surface.

${ }^{13} \mathrm{C} \mathrm{CP/MAS} \mathrm{spectra} \mathrm{of} \mathrm{thermoplastic} \mathrm{starch,} \mathrm{starch/PVOH} \mathrm{blends}$ and their clay nanocomposites are shown in Figure 2 after a conditioning/aging time of 105 days. The starch resonances at 103, 83, 74 and 62 p.p.m. were assigned to C-1, C-4, C-2, 3, 5 and C-6, respectively. ${ }^{41,42}$ Minor resonances at 20 and 33 p.p.m. (peaks 1 and 2) are due to the propyl substitution $(\sim 4$ to $5 \%)$ at C-6 of the starch,

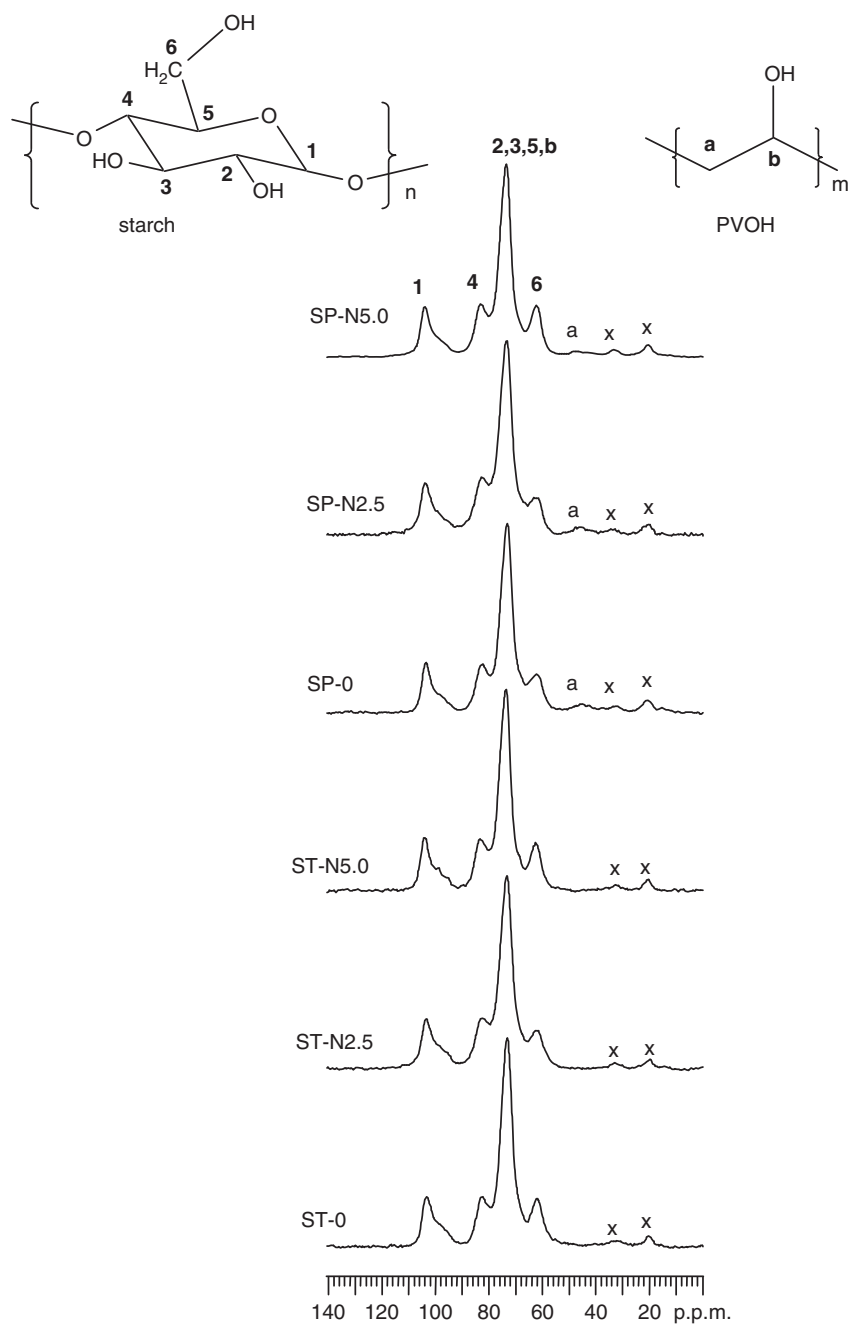

Figure $2{ }^{13} \mathrm{C}$ CP/MAS NMR spectra of ST-0, -N2.5, -N5.0 and SP-0, -N2.5, -N5.0 after aging for 105 days. Peaks ' $x$ ' are derived from propylene substitution. derived from the structure modification. For the system containing $\mathrm{PVOH}$, a minor peak at 46 p.p.m. (peak 3) was detected, corresponding to the $-\mathrm{CH}_{2}-$ resonance of $\mathrm{PVOH}$, whereas the $-\mathrm{CHOH}-$ resonance overlapped with the starch signals. No significant linewidth broadening (linewidth variation within $20-30 \mathrm{~Hz}$ ) was observed for the systems containing clay nanoparticles, suggesting that the effect of the paramagnetic $\mathrm{Fe}^{3+}$ ions in the clay on the starch matrix was much weaker than those observed for the organic modifiers directly bonded on the surface of clay platelets. ${ }^{34}$ The spectra observed from samples with a shorter aging time displayed a similar behavior.

${ }^{1} \mathrm{H} \mathrm{T}_{1 \rho}$ data of samples aged for 105 days were observed by ${ }^{13} \mathrm{C}$ resonances, as listed in Table 2 . The $\mathrm{T}_{1 \rho}$ values for ST- 0 and SP- 0 were around $3.5 \mathrm{~ms}$. Dispersing 2.5 or $5.0 \mathrm{wt} \%$ of clay did not produce a large variation in $T_{1 \rho}$ values. As the effect of reduction in relaxation time caused by paramagnetic $\mathrm{Fe}^{3+}$ ions on ${ }^{1} \mathrm{H} \mathrm{T}_{1 \rho}$ relaxation will be enhanced with an increased amount of NaMMT, the minimal change in ${ }^{1} \mathrm{H} \mathrm{T}_{1 \rho}$ data, as shown in Table 2, indicates that the distance between clay platelets in the starch matrix was far longer than the efficient spin-diffusion pathway of $1-3 \mathrm{~nm}$ during the ${ }^{1} \mathrm{H} \mathrm{T}_{1 \rho}$ time scale, ${ }^{43-45}$ even in the case of an exfoliated system.

Molecular motions could also cause a variation in ${ }^{1} \mathrm{H} \mathrm{T}_{1 \rho}$ relaxation. The starch matrix of these starch-clay nanocomposites was plasticized with water; thus, moisture content (shown in Figure 3) would have a key role in the motional effect. Note that the moisture content values were slightly different among the samples, although they experienced the same conditioning, and the data decreased by 2 $\mathrm{wt} \%$ for all the samples during the aging period. After aging for 90 days, ST-0 and SP-0 contained slightly more moisture than their corresponding nanocomposites, possibly because of the formation of more stable-phase structures with a new equilibrium distribution of bound and free water in the systems. The difference in moisture content, although not significant, might result in different plasticization effects in the nanocomposite samples. On the other hand, the interactions between NaMMT clay surfaces and the starch matrix in an exfoliated structure would also be likely to result in a motional restriction. However, the ${ }^{1} \mathrm{H} \mathrm{T}_{1 \rho}$ data indicate that these motional effects were not significant at room temperature, which is far below the glass transition temperature of these samples $\left(T_{\mathrm{g}}>65^{\circ} \mathrm{C}\right.$ when the moisture content is below 13\%). ${ }^{46}$ Such effects could be more pronounced at high temperatures.

A significant effect of paramagnetic $\mathrm{Fe}^{3+}$ ions was obtained in the ${ }^{1} \mathrm{H} \mathrm{T}_{1}$ measurements for these samples. A single ${ }^{1} \mathrm{H} \mathrm{T}_{1}$ component was observed for the starch matrix in all of these aged ST and SP samples through ${ }^{13} \mathrm{C}$ resonances using the $\mathrm{CP}$ method. Figure 4 shows the fitting curves of the ${ }^{1} \mathrm{H} \mathrm{T}_{1}$ data detected at 74 p.p.m. of their ${ }^{13} \mathrm{C} \mathrm{CP} /$ MAS spectra. The ${ }^{1} \mathrm{H} \mathrm{T}_{1}$ decays became much faster, resulting in a short $\mathrm{T}_{1}$ value, with an increasing amount of NaMMT in the starchclay nanocomposites. The ${ }^{1} \mathrm{H} \mathrm{T}_{1}$ values of the aged samples are listed in Table 3 , in addition to the ${ }^{1} \mathrm{H} \mathrm{T}_{1}$ values for the moisture in the same

Table $2{ }^{1} \mathrm{H} \mathrm{T}_{1 \rho}$ (ms) of the starch-clay nanocomposites ( $300 \mathrm{MHz}$ )

\begin{tabular}{lccc}
\hline Sample & 104 p.p.m. & 74 p.p.m. & 62 p.p.m. \\
\hline ST-0 & $3.4 \pm 0.3$ & $3.5 \pm 0.3$ & $3.5 \pm 0.3$ \\
ST-N2.5 & $3.0 \pm 0.2$ & $3.2 \pm 0.1$ & $3.2 \pm 0.3$ \\
ST-N5.0 & $3.5 \pm 0.2$ & $3.7 \pm 0.1$ & $3.5 \pm 0.5$ \\
SP-0 & $3.4 \pm 0.2$ & $3.5 \pm 0.1$ & $3.5 \pm 0.3$ \\
SP-N2.5 & $3.0 \pm 0.1$ & $2.8 \pm 0.1$ & $2.7 \pm 0.2$ \\
SP-N5.0 & $3.8 \pm 0.2$ & $3.4 \pm 0.1$ & $3.3 \pm 0.2$ \\
\hline
\end{tabular}




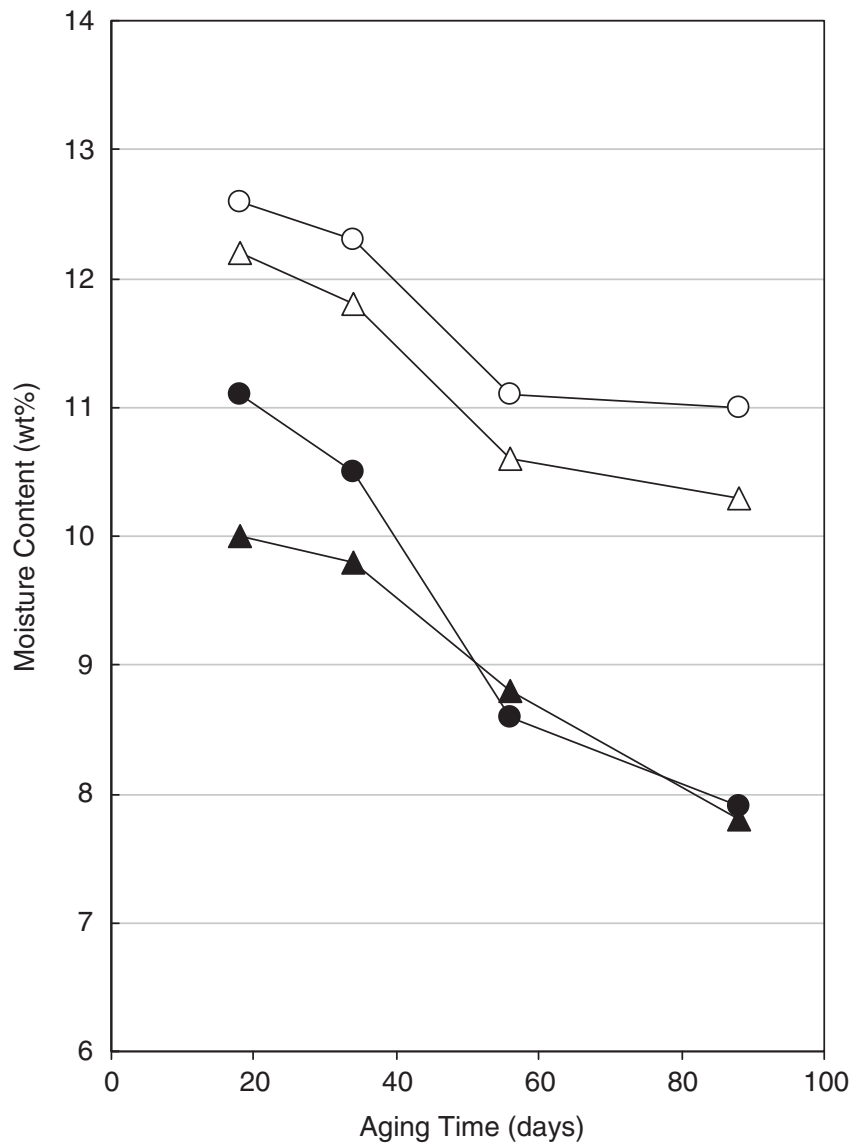

Figure 3 Moisture content data of ST-0 $(O)$, ST-N5.0 $(\bullet)$, SP-O $(\triangle)$ and SPN5.0 ( $\mathbf{\Lambda})$ over the aging period of 105 days.

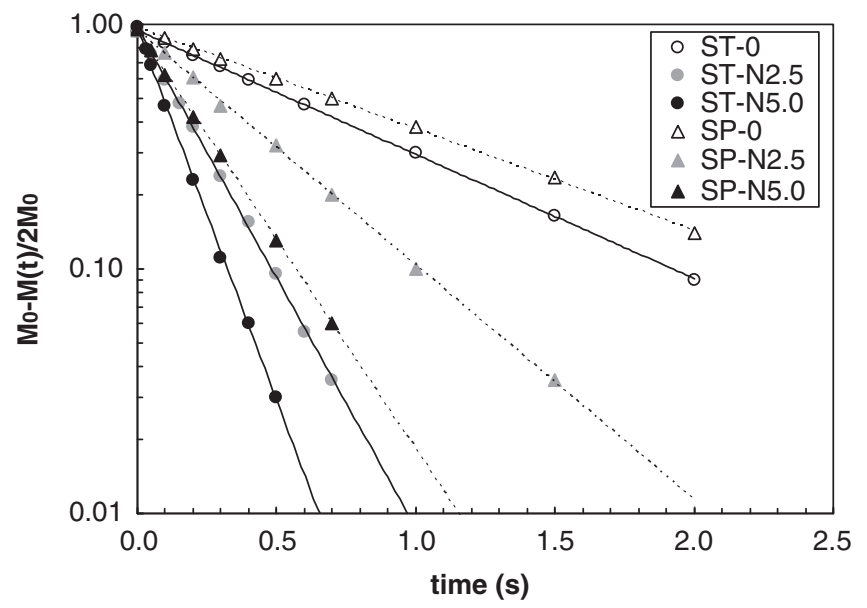

Figure 4 The fitting curves of ${ }^{1} \mathrm{H} \mathrm{T}_{1}$ data observed at 74 p.p.m. of the $\mathrm{CP} /$ MAS NMR spectra for ST-0, -N2.5, -N5.0 and SP-0, -N2.5, -N5.0 after aging for 105 days.

systems observed by ${ }^{1} \mathrm{H}$ MAS spectra. Note that these $T_{1}$ values detected for the starch and moisture components were relatively close to each other in each sample after aging for 105 days, suggesting strong hydrogen-bonding interactions between water molecules and the starch matrix, resulting in an efficient spin diffusion within these
Table $3{ }^{1} \mathrm{H} \mathrm{T}_{1}$ (s) of the starch-clay nanocomposites after aging (300 MHz)

\begin{tabular}{lcc}
\hline Sample & Starch & Moisture \\
\hline ST-0 & $0.85 \pm 0.01$ & $0.82 \pm 0.02$ \\
ST-N2.5 & $0.21 \pm 0.01$ & $0.19 \pm 0.01$ \\
ST-N5.0 & $0.13 \pm 0.01$ & $0.13 \pm 0.01$ \\
SP-0 & $1.09 \pm 0.01$ & $1.06 \pm 0.02$ \\
SP-N2.5 & $0.45 \pm 0.01$ & $0.42 \pm 0.01$ \\
SP-N5.0 & $0.28 \pm 0.01$ & $0.22 \pm 0.01$ \\
\hline
\end{tabular}

systems to average out the relaxation rates of the two components. For the systems with $\mathrm{PVOH}$ as an additive, the ${ }^{1} \mathrm{H} \mathrm{T}_{1}$ values of the starch matrix were also reduced when the clay content increased. The effect of $\mathrm{Fe}^{3+}$ ions on the ${ }^{1} \mathrm{H} \mathrm{T}_{1}$ of the starch matrix is determined by the amount of $\mathrm{Fe}^{3+}$ ions due to the clay content, and the clay dispersion in the systems. When the clay content is constant, a much shortened ${ }^{1} \mathrm{H}$ $\mathrm{T}_{1}$ would be observed for an exfoliated nanocomposite, as the exfoliation of the clay sheets would result in a high clay-starch interfacial area, short average distance between clay platelets and a short spin-diffusion pathway in the starch matrix. The ${ }^{1} \mathrm{H} \mathrm{T}_{1}$ values in the systems with $\mathrm{PVOH}$ as an additive did not decrease as much as those without $\mathrm{PVOH}$ in the nanocomposites. This is consistent with their clay dispersion, as examined by TEM (Figure 1). Such changes in the ${ }^{1} \mathrm{H} \mathrm{T}_{1}$ values of the starch matrix can be used as a measure of the quality of clay dispersion in the nanocomposites.

\section{Correlation between ${ }^{1} \mathbf{H} \mathrm{T}_{1}$ and clay dispersion}

The observed ${ }^{1} \mathrm{H} \mathrm{T}_{1}$ value of the starch matrix in the nanocomposites is attributed to several factors, as listed below:

$$
\left(1 / T_{1}\right)=\left(1 / T_{1(0)}\right)+\left(1 / T_{1 \text { para }}\right)+\left(1 / T_{1 \text { (motional })}\right)
$$

where $T_{1(0)}$ is the value for starch without dispersing nano-clay and $T_{1 \text { para }}$ is the effect due to interactions with the paramagnetic $\mathrm{Fe}^{3+}$ ions. $T_{1 \text { (motional) }}$ is an effect due to the interactions between starch macromolecules and nano-clay platelets. When the interaction between starch and the surface of the nano-clay is strong, a motional restriction to the starch matrix will occur. On the other hand, when the clay is heavily modified by organic surfactants to enhance the dispersion capability and function as additional plasticizers, the molecular motions, or at least the local molecular motions, of starch chains will be enhanced. At room temperature, which is far below $T_{\mathrm{g}}$ of the starch matrix (above $65^{\circ} \mathrm{C}$ ), ${ }^{46}$ motional restriction will increase the $T_{1}$ value, whereas the plasticization effect might decrease the $T_{1}$ value. For the wheat gluten-clay nanocomposites studied previously, ${ }^{47}$ the clay was modified with $30 \mathrm{wt} \%$ methyl tallow bis-2-hydroxyethyl quaternary ammonium chloride, which functions as an efficient plasticizer for wheat gluten. The decrease in $T_{1}$ values of the nanocomposites could be due to a combination of the plasticizing effect and the paramagnetic effect. In that case, quantifying the paramagnetic effect would be difficult.

For the starch-clay nanocomposites studied in this paper, the NaMMT nano-clay was not modified with organic compounds and the motional effect on the relaxation of the starch matrix was not significant, as suggested by the ${ }^{1} \mathrm{H} \mathrm{T}_{1 \rho}$ data, which should be more sensitive to local molecular motions than ${ }^{1} \mathrm{H} \mathrm{T}_{1}$ measurements. Thus, the motional effect can be ignored and only the $T_{1(0)}$ and $T_{1 \text { para }}$ components need to be considered:

$$
\left(1 / T_{1}\right)=\left(1 / T_{1(0)}\right)+\left(1 / T_{1 \text { para }}\right)
$$


Table $4{ }^{1} \mathrm{H} \mathrm{T}_{1 \text { para }}(\mathrm{s})$ of the starch-clay nanocomposites after aging (300 MHz)

\begin{tabular}{lcc}
\hline Sample & Starch & Moisture \\
\hline ST-N2.5 & $0.28 \pm 0.01$ & $0.24 \pm 0.01$ \\
ST-N5.0 & $0.15 \pm 0.01$ & $0.15 \pm 0.01$ \\
SP-N2.5 & $0.77 \pm 0.01$ & $0.70 \pm 0.01$ \\
SP-N5.0 & $0.38 \pm 0.01$ & $0.27 \pm 0.01$ \\
\hline
\end{tabular}

This equation was used to characterize nylon-clay nanocomposites, as previously reported. ${ }^{33,35,37}$ The paramagnetic effect $T_{1 \text { para }}$ for starch and starch/PVOH nanocomposites can be calculated directly from equation (2), and these data are shown in Table 4 . These $T_{1 \text { para }}$ values should be correlated to the surface-to-volume ratio, reflecting the clay dispersion in the starch matrix, as described previously: ${ }^{33,35,37}$

$$
S_{\text {clay }} / V_{\text {starch }} \propto 1 / T_{\text {para }}
$$

For a starch-clay system with a given clay concentration, the higher the clay-starch interfacial area the shorter the average distance between clay platelets $(\langle\bar{D}\rangle)$ within the starch matrix, and the shorter the $T_{1 \text { para }}$ value of the starch matrix. Therefore,

$$
<\bar{D}>\propto T_{1 \text { para }}
$$

This correlation between the $T_{1 \text { para }}$ value and the separation of clay platelets $(\langle\bar{D}\rangle$ data) provides a simple method for characterizing the clay dispersion in nanocomposites. The surface-to-volume ratio can be calculated for a perfectly exfoliated system if the concentration of clay, the clay shape and the densities of all components in the system are known. In reality, such perfect systems do not exist, and the establishment of the correlation between the $T_{1 \text { para }}$ value and the surface-tovolume ratio requires knowledge of clay dispersion. Such a correlation can also be changed when the clay concentration varies over a wide range. A detailed discussion of these issues can be found in VanderHart's publications. ${ }^{33-36}$ In this paper, we only intend to conduct a qualitative analysis of the clay dispersion for starch-clay nanocomposites.

The ST-N2.5 sample was a nearly perfect exfoliated system, as observed by TEM (Figure 1). Taking the clay thickness to be $1 \mathrm{~nm}$, the clay length to be $100 \mathrm{~nm}$ and the densities of clay and the starch matrix to be 2.7 and $1.1 \mathrm{~g} \mathrm{~cm}^{-3}$, respectively, and using a perfect exfoliation model of oriented disk composites ${ }^{48,49}$ (shown in Figure 5), in which the volume of each clay platelet is calculated as $\pi(100 / 2)^{2} \times 1 \mathrm{~nm}^{3}$ and the volume ratio of starch is calculated as NaMMT $=(97.5 / 1.1):(2.5 /$ $2.7)$, the average distance $\langle\bar{D}>$ between clay platelets was calculated to be $39 \mathrm{~nm}$. If using the orthogonally shaped model, ${ }^{50}$ in which the volume of each clay platelet is calculated as $100 \times 100 \times 1 \mathrm{~nm}^{3}$, the obtained $\langle\bar{D}\rangle$ value is $44 \mathrm{~nm}$. It seems reasonable to take a value of $40 \mathrm{~nm}$ as the $\langle\bar{D}\rangle$ value for the ST-N2.5 sample, as the clay shape should be between the two models but close to the disk shape. When doubling the amount of nano-clay in the starch matrix (ST-N5.0), and if the system remained perfectly exfoliated, the $\langle\bar{D}\rangle$ value and the $T_{1 \text { para }}$ value should be reduced to half of the values for ST-N2.5. The values listed in Table 3 show that $T_{1 \text { para }}$ for ST-N5.0 was indeed reduced to nearly half of that for ST-N2.5, suggesting that the $\langle\bar{D}>$ value of ST-N5.0 should be around $20 \mathrm{~nm}$. This scale is much longer than the effective spin-diffusion scale within the ${ }^{1} \mathrm{H} \quad \mathrm{T}_{1 \rho}$ time (1-3 nm), and thus no significant change in $\mathrm{T}_{1 \rho}$ values was detected, as seen in Table 2. The TEM image of ST-N5.0 (Figure 1) shows that the system remained exfoliated, but the uniformity of clay dispersion was reduced. Longer $T_{1 \text { para }}$ values were obtained for the samples

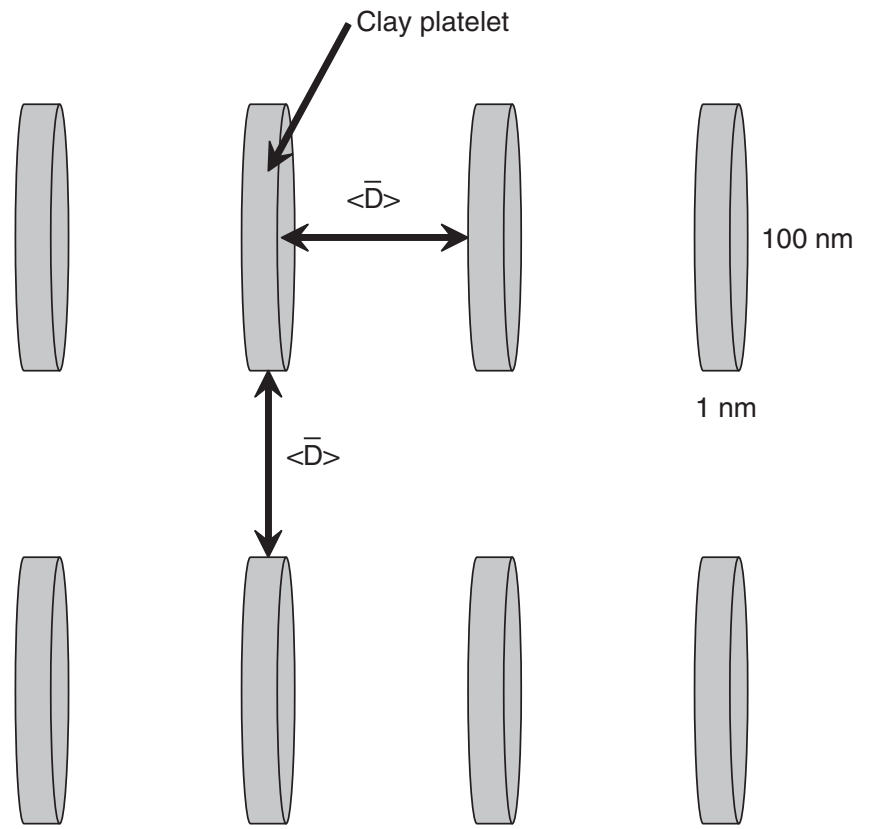

Figure $5 \mathrm{~A}$ perfect exfoliation model of oriented disk clay platelets in a starch matrix.

Table $5{ }^{1} \mathrm{H} \mathrm{T}_{1}$ (s) and ${ }^{1} \mathrm{H} \mathrm{T}_{1 \text { para }}$ (s) of the starch-clay nanocomposites after aging $(20 \mathrm{MHz})$

\begin{tabular}{lcc}
\hline Sample & ${ }^{1} H T_{1}$ & ${ }^{1} H T_{\text {lpara }}$ \\
\hline ST-0 & $0.056 \pm 0.004$ & - \\
ST-N2.5 & $0.022 \pm 0.002$ & 0.036 \\
ST-N5.0 & $0.015 \pm 0.001$ & 0.020 \\
SP-0 & $0.070 \pm 0.004$ & - \\
SP-N2.5 & $0.041 \pm 0.002$ & 0.099 \\
SP-N5.0 & $0.030 \pm 0.002$ & 0.053 \\
\hline
\end{tabular}

containing $5 \mathrm{wt} \% \mathrm{PVOH}$, suggesting that the starch matrix experienced weaker interactions with the paramagnetic $\mathrm{Fe}^{3+}$ ions in the clay, as compared with the samples without $\mathrm{PVOH}$ in the nanocomposites.

The ${ }^{1} \mathrm{H} \mathrm{T}_{1}$ parameters of these nanocomposites were also measured in a static magnetic field at $20 \mathrm{MHz}$; the data and the calculated corresponding $T_{1 \text { para }}$ values are shown in Table 5 . Although the $T_{1}$ data became much smaller at the low magnetic field, the same trend was present: the $T_{1 \text { para }}$ value of ST-N5.0 is just over half of that for STN2.5. Thus, the $\langle\bar{D}\rangle$ value of ST-N5.0 should be around $22 \mathrm{~nm}$, using the same correlation between $T_{1 \text { para }}$ and $\langle\bar{D}>$ (equation (4)). The samples containing $5 \mathrm{wt} \%$ of PVOH (SP-N2.5 and -N5.0) also displayed longer $T_{1 \text { para }}$ values, indicating weaker interactions between the paramagnetic $\mathrm{Fe}^{3+}$ ions in the clay and polymer matrix.

Bearing in mind that the spin-diffusion effect within the ${ }^{1} \mathrm{H} \mathrm{T}_{1}$ time scale is only effective within several tens of nanometers in a rigid polymer system such as thermally processed starch at room temperature, this methodology is more suitable for exfoliated systems such as ST-N2.5 and -N5.0 samples. For intercalated and flocculated systems, multiple components of ${ }^{1} \mathrm{H} \mathrm{T} \mathrm{T}_{1}$ might be obtained, corresponding to the polymer components with strong, weak or no interactions with the paramagnetic $\mathrm{Fe}^{3+}$ ions in the clay. The obtained ${ }^{1} \mathrm{H} T_{1 \text { para }}$ values of SP-N samples mainly reflect the interactions between polymer 
components and smaller clay tactoids (three to five particles) dispersed in the starch matrix, as seen in the TEM images in Figure 1. Thus, the $\langle\bar{D}\rangle$ values of $\sim 110$ and $55 \mathrm{~nm}$, obtained for SP-N2.5 and -N5.0, respectively, using the same correlation between $T_{1 \text { para }}$ and $\langle\bar{D}>$ of the exfoliated ST systems, might only reflect the situation of these regions. Large clay aggregates would not have a significant contribution to the decrease in $T_{1}$ values and the proportion of the longer distances between clay platelets was missed or underestimated. As the correlation between $T_{1 \text { para }}$ and $\langle\bar{D}\rangle$ values would be quite different for intercalated, flocculated and exfoliated systems, a crosscomparison among these systems might only provide a qualitative indication.

Nevertheless, the NMR study provides a simple bulk analysis method to indicate clay dispersion or the degree of exfoliation, reflecting an average result of all samples in the sample rotor for the MAS experiment $(\sim 100 \mathrm{mg})$ or in the sample tube at a static low magnetic field (up to $3-5 \mathrm{~g}$ ), rather than a very small specific area of the sample as detected by TEM or wide-angle X-ray diffraction, both of which have been commonly used in the study of nanocomposites. On the other hand, the clay dispersion observed from TEM images can be overestimated when clay platelets are not oriented directly parallel to the electron beam, because multiple clay platelets may be observed in the TEM image. ${ }^{37}$ Sampling specimens could be difficult for some systems, and image contrast could also influence the observation of TEM images.

\section{Aging effect on clay dispersion}

Thermally extruded starch-based materials usually experience a slow recrystallization process over a long period of time., ${ }^{40-52}$ The additives in the materials and environmental conditions such as humidity and temperature have key roles in the recrystallization process. An evolution of single and double helical crystalline structures was observed for high amylose-content starch after aging, but the recrystallization process was slower for amylopectin starch. Although the overall crystallinity in the systems was low, an increase in crystallinity will affect the mechanical properties of the starch-based materials; they usually become brittle after long-term aging. The decrease in moisture content, shown in Figure 3, could also contribute to the increased brittleness of the starch matrix after aging. For starch-clay nanocomposites, the clay dispersion during such an aging process might also be modified, thus resulting in changes in performance. The aging effect on the mechanical properties and morphologies of the starch-clay systems will be reported on a later date; only the indicative result of the clay dispersion of the nanocomposites during the aging process was studied in this paper using the high-resolution solid-state NMR technique.

${ }^{1} \mathrm{H} \mathrm{T}_{1}$ values of the starch matrix and moisture in the systems were observed for ST-N5.0 and SP-N5.0 samples over the aging period under $\mathrm{RH}=50 \%$ at room temperature, and their corresponding $T_{1 \text { para }}$ values were calculated and are shown in Figure 6 . Note that the $T_{1 \text { para }}$ values of the starch matrix increased during the initial 40 days, suggesting a decrease in the degree of exfoliation, but the values became constant after aging for 40-60 days. The ST-N5.0 sample experienced only a very small increase in $T_{1 \text { para }}$, suggesting a similar level of increase in the $\langle\bar{D}\rangle$ value, from 19 to $21 \mathrm{~nm}$, during the initial 40-60 days. It seems that the recrystallization effect of starch during the aging process did not produce a significant reduction in clay dispersion. A more significant increase in $T_{1 \text { para }}$ was obtained for the SP-N5.0 system; the $T_{1 \text { para }}$ value of the starch matrix increased nearly $60 \%$ after aging over the initial 60 days, corresponding to an increase in the $\langle\bar{D}\rangle$ value from 33 to $55 \mathrm{~nm}$, as calculated by this

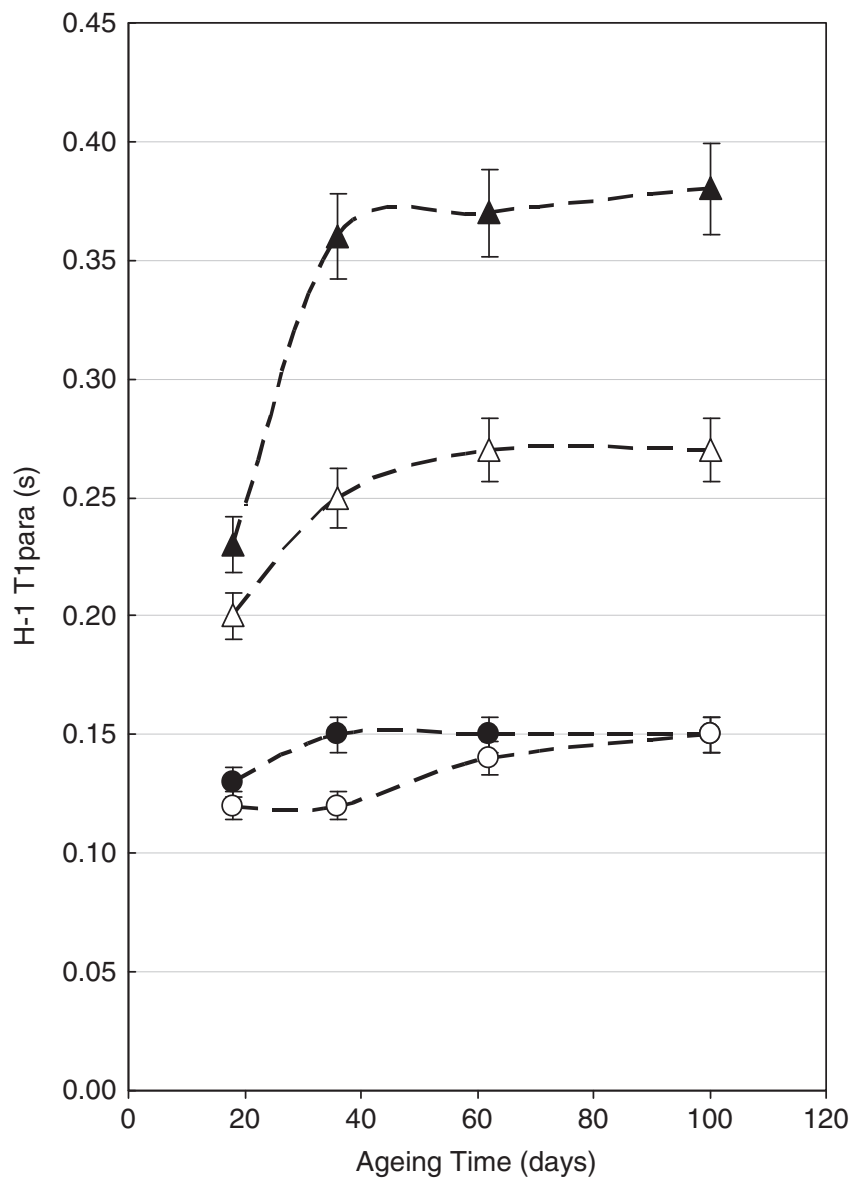

Figure $6{ }^{1} \mathrm{H} \mathrm{T}_{1 \text { para }}$ data of ST-N5.0 (•, starch; O, moisture) and SP-N5.0 ( $\mathbf{\Lambda}$, starch; $\triangle$, moisture) over the aging period of 105 days.

method. The molecular motions of $\mathrm{PVOH}$ might function as a driving force to reach a more stable interaction between the PVOH chains and the clay platelets during the aging period, which results in a significant reduction in the degree of clay exfoliation in the starch matrix. Note that the $T_{1 \text { para }}$ values of the starch matrix in SP-N5.0 increased more significantly than those of moisture in the systems after aging, suggesting that the water molecules still retained their strong interactions with the clay surface, with less influence of the addition of PVOH.

\section{CONCLUSIONS}

High-resolution solid-state NMR has provided a simple bulk analysis method to study the degree of clay dispersion in starch-clay nanocomposites. A starch system containing $2.5 \mathrm{wt} \%$ nano-clay appeared as an exfoliated nanocomposite, with the average distance between clay platelets $(<\bar{D}>)$ in the starch matrix around $40 \mathrm{~nm}$. Increasing the amount of nano-clay to $5.0 \mathrm{wt} \%$ in the matrix reduced the $\langle\bar{D}\rangle$ value to around $20 \mathrm{~nm}$. However, when $5 \mathrm{wt} \% \mathrm{PVOH}$ was used as an additive in the systems, the $\langle\bar{D}>$ value became larger because of the formation of aggregated structures. The aging effect on the exfoliation of starch-clay nanocomposites was minimal, but it was more pronounced in systems containing $\mathrm{PVOH}$, in which $\langle\bar{D}\rangle$ values significantly increased after aging over the initial 60 days. The starch recrystallization during the aging process did not significantly influence the clay dispersion, but the molecular motions of $\mathrm{PVOH}$ during the aging period could function as a driving force to reach a 
more stable interaction between $\mathrm{PVOH}$ chains and clay platelets, causing a significant reduction in the degree of clay exfoliation in the starch matrix.

1 Averous, L. Biodegradable multiphase systems based on plasticized starch: a review. J. of Macromol. Sci. Part C-Polym. Rev. C44, 231-274 (2004).

2 Smith, R. Biodegradable Polymers for Industrial Applications (Woodhead Publishing Ltd and CRC Press LLC, Cambridge, Boca Raton, Boston, New York, Washington, DC, 2005).

3 Wool, R. P. \& Sun, X. S. Bio-Bassed Polymers and Composites (Elserier Academic Press, Burlington, San Diego, London, 2005).

4 Van Soest, J., Hulleman, S., De Wit, D. \& Vliegenthart, J. Changes in the mechanical properties of thermoplastic potato starch in relation with changes in $\beta$-type crystallinity. Carbohydr. Polym. 29, 225-232 (1996).

5 De Graaf, R., Karman, A. \& Janssen, L. Material properties and glass transition temperatures of different thermoplastic starches after extrusion processing. Starch/ Starke 55, 80-86 (2003).

$6 \mathrm{Yu}, \mathrm{L}$. \& Christie, G. Microstructure and mechanical properties of orientated thermoplastic starches. J. Mater. Sci. 40, 111-116 (2005).

7 Jun, C. L. Reactive blending of biodegradable polymers: PLA and starch. J. Polym. Environ. 8, 33-37 (2000).

8 Biresaw, C. \& Carriere, C. J. Correlation between mechanical adhesion and interfacial properties of starch/biodegradable polyester blends. J. Polym. Sci. Part B: Polym. Phys. 39, 920-930 (2001).

9 Dubois, P. \& Narayan, R. Biodegradable compositions by reactive processing of aliphatic polyester/polysaccharide blends. Macromol. Symp. 198, 233-243 (2003).

10 Zhang, J. F. \& Sun, X. Mechanical properties of poly(lactic acid)/starch composites compatibilized by maleic anhydride. Biomacromolecules 5, 1446-1451 (2004).

11 Schwach, E. \& Averous, L. Starch-based biodegradable blends: morphology and interface properties. Polym. Int. 53, 2115-2124 (2004).

12 Kalambur, S. \& Rizvi, S. Biodegradable and functionally superior starch-polyester nanocomposites from reactive extrusion. J. Appl. Polym. Sci. 96, 1072-1082 (2005).

13 Liu, H., Xie, F., Yu, L., Chen, L. \& Li, L. Thermal processing of starch-based polymers. Prog. Polym. Sci. 34, 1348-1368 (2009).

14 Giannelis, E. P. Polymer-layered silicate nanocomposites: synthesis, properties and applications. Appl. Organomet. Chem. 12, 675-680 (1998).

15 LeBaron, P. C., Wang, Z. \& Pinnavaia, T. J. Polymer-layered silicate nanocomposites: an overview. Appl. Clay Sci. 15, 11-29 (1999).

16 Schmidt, D., Shah, D. \& Giannelis, E. P. New advances in polymer/layered silicate nanocomposites. Curr. Opin. Solid State \& Mater. Sci. 6, 205-212 (2002).

17 Bharadwaj, R. K., Mehrabi, A. R., Hamilton, C., Trujillo, C., Murga, M., Fan, R., Chavira, A. \& Thompson, A. K. Structure-property relationships in cross-linked polyester-clay nanocomposites. Polymer 43, 3699-3705 (2002).

18 Ray, S. S., Okamoto, K. \& Okamoto, M. Structure-property relationship in biodegradable poly(butylene succinate)/layered silicate nanocomposites. Macromolecules 36, 2355-2367 (2003).

19 Rhim, J. W. \& Ng, P. K. W. Natural biopolymer-based nanocomposite films for packaging applications. Crit. Rev. Food. Sci. Nutr. 47, 411-433 (2007).

20 Park, H., Li, X., Jin, C., Park, C., Cho, W. \& Ha, C. Preparation and properties of biodegradable thermoplastic starch/clay hybrids. Macromol. Mater. Eng. 287, 553-558 (2002).

21 Park, H., Lee, W., Park, C., Cho, W. \& Ha, C. Environmentally friendly polymer hybrids part I mechanical, thermal, and barrier properties of thermoplastic starch/clay nanocomposites. J. Mater. Sci. 38, 909-915 (2003).

22 Wilhelm, H., Sierakowski, M., Souza, G. \& Wypych, F. Starch films reinforced with mineral clay. Carbohydr. Polym. 52, 101-110 (2003).

23 McGlashan, S. \& Halley, P. Preparation and characterisation of biodegradable starchbased nanocomposite materials. Polym. Int. 52, 1767-1773 (2003).

24 Fisher, H. Polymer nanocomposites: from fundamental research to specific applications. Mater. Sci. Eng. C23, 763-772 (2003).

25 Kalambur, S. \& Rizvi, S. Starch-based nanocomposites by reactive extrusion processing. Polym. Int. 53, 1413-1416 (2004).
26 Huang, M., Yu, J. \& Ma, X. Studies on the properties of montmorillonite-reinforced thermoplastic starch composites. Polymer 45, 7017-7023 (2004).

27 Chen, B. \& Evans, J. Thermoplastic starch-clay nanocomposites and their characteristics. Carbohydr. Polym. 61, 455-463 (2005).

28 Dean, K., Yu, L. \& Wu, D. Y. Preparation and characterization of melt-extruded thermoplastic starch/clay nanocomposites. Comp. Sci. Tech. 67, 413-421 (2007).

29 Dean, K., Do, M., Petinakis, E. \& Yu, L. Key interactions in biodegradable thermoplastic starch/poly(vinyl alcohol)/montmorillonite micro- and nanocomposites. Comp. Sci. Tech. 68, 1453-1462 (2008).

30 Alexison, D. E. \& Russell, K. Characterization of polymers by means of ${ }^{13} \mathrm{C}$ NMR spectroscopy. Prog. Polym. Sci. 11, 221-282 (1985).

31 McBrierty, V. \& Packer, K. Nuclear Magnetic Resonance in Solid Polymers (Cambridge University Press, Cambridge, UK, 1993).

32 Saito, H., Ando, I. \& Naito, A. Solid State NMR Spectroscopy for Biopolymers: Principles and Applications (Springer, Dordrecht, The Netherlands, 2006).

33 VanderHart, D. L., Asano, A. \& Gilman, J. W. NMR measurements related to claydispersion quality and organic-modifier stability in nylon-6/clay nanocomposites. Macromolecules 34, 3819-3822 (2001).

34 VanderHart, D. L., Asano, A. \& Gilman, J. W. Solid-state NMR investigation of paramagnetic nylon- 6 clay nanocomposites. 1 . Crystallinity, morphology, and the direct influence of $\mathrm{Fe}^{3+}$ on nuclear spins. Chem. Mater. 13, 3781-3795 (2001).

35 VanderHart, D. L., Asano, A. \& Gilman, J. W. Solid-state NMR investigation of paramagnetic nylon- 6 clay nanocomposites. 2 . Measurement of clay dispersion, crystal stratification, and stability of organic modifiers. Chem. Mater. 13, 3796-3809 (2001).

36 Bourbigot, S., VanderHart, D. L., Gilman, J. W., Awad, W. H., Davis, R. D., Morgan, A. B. \& Wilkie, C. A. Investigation of nanodispersion in polystyrene-montmorillonite nanocomposites by solid-state NMR. J. Polym. Sci. Part B: Polym. Phys. 41, 3188-3213 (2003).

37 Bertmer, M., Wang, M., Kruger, M., Blumich, B., Litvinov, V. \& van Es, M. Structural changes from the pure components to nylon 6-montmorillonite nanocomposites observed by solid-state NMR. Chem. Mater. 19, 1089-1097 (2007).

38 Mao, L., Imam, S., Gordon, S., Cinelli, P. \& Chiellini, E. Extruded cornstarch-glycerolpolyvinyl alcohol blends: mechanical properties, morphology, and biodegradability. J. Polym. Environ. 8, 205-211 (2000).

39 Ikejima, T., Yoshie, N. \& Inoue, Y. Influence of tacticity and molecular weight of poly(vinyl alcohol) on crystallization and biodegradation of poly(3-hydroxybutyric acid)/ poly(vinyl alcohol) blend films. Polym. Degra. Stability 66, 263-270 (1999).

40 Fishman, M., Coffin, D., Onwulata, C. \& Willett, J. Two stage extrusion of plasticized pectin/poly(vinyl alcohol) blends. Carbohydr. Polym. 65, 421-429 (2006).

41 Gidley, M. J. \& Bociek, S. M. Molecular organization in starches: a ${ }^{13} \mathrm{C}$ CP/MAS NMR study. J. Am. Chem. Soc. 107, 7040-7044 (1985)

42 Zhang, X., Golding, J. \& Burgar, I. Thermal decomposition chemistry of starch studied by ${ }^{13} \mathrm{C}$ high-resolution solid-state NMR spectroscopy. Polymer 43, 5791-5796 (2002).

43 Zhang, X., Takegoshi, K. \& Hikichi, K. Poly(vinyl phenol)/poly(methyl acrylate) and poly(vinyl phenol)/poly(methyl methacrylate) blends: hydrogen bonding, miscibility, and blending effects on molecular motions as studied by C-13 CP/MAS NMR. Macromolecules 24, 5756-5762 (1991).

44 Zhang, X., Takegoshi, K. \& Hikichi, K. The composition dependence of the miscibility and the phase structure of amorphous/crystalline polymer blends as studied by solidstate high-resolution C-13 NMR. Macromolecules 25, 2336-2340 (1992).

45 Zhang, X. \& Solomon, D. H. Phase structures of hexamine crosslinked novolac blends: 1. Blends with poly(methyl methacrylate). Macromolecules 27, 4919-4926 (1994).

46 Liu, P., Yu, L., Liu, H., Chen, L. \& Li, Lin. Glass transition temperature of starch studied by a high-speed DSC. Carbohy. Polym. 77, 250-253 (2009).

47 Zhang, X., Do, M., Dean, K., Hoobin, P. \& Burgar, I. Wheat gluten-based natural polymer nanoparticle composites. Biomacromolecules 8, 345-353 (2007).

48 Fredrickson, G. H. \& Bicerano, J. Barrier properties of oriented disk composites. J. Chem. Phys. 110, 2181-2188 (1999).

49 Choudalakis, G. \& Gotsis, A. D. Permeability of polymer/clay nanocomposites: a review. Eur. Polym. J. 45, 967-984 (2009).

50 Van Soest, J., de Wit, D. \& Vliegenthart, J. Mechanical properties of thermoplastic waxy maize starch. J. Appl. Polym. Sci. 61, 1927-1937 (1996).

51 Van Soest, J., Hulleman, S., de Wit, D. \& Vliegenthart, J. Crystallinity in starch bioplastics. Ind. Crops Prod. 5, 11-22 (1996).

52 Van Soest, J. \& Knooren, N. Influence of glycerol and water content on the structure and properties of extruded starch plastic sheets during aging. J. Appl. Polym. Sci. 64 1411-1422 (1997). 